\section{§1. Improvement of Vanadium Alloys by Precipitate Control for Structural Components of Fusion Reactors}

Muroga, T., Nagasaka, T., Nishimura, A. Chen, J.M. (Southwestern Institute of Physics.)

Vanadium alloys are attractive candidate fusion reactor materials especially because of its excellent low activation properties. Based on recent research, $\mathrm{V}-4 \mathrm{Cr}-4 \mathrm{Ti}$ has been selected as a leading candidate alloy. For application to the structural components, both ductility at low temperature and strength at high temperature are required. The mechanical properties of the alloy are subject to distribution of interstitial impurities $(\mathrm{C}, \mathrm{O}$ and $\mathrm{N})$ in solution and precipitates of $\mathrm{Ti}$ combined with the impurities. This paper summarizes recent studies to enhance properties of vanadium alloys by controlling the precipitates through thermal and mechanical treatments.

In the program of fabricating high purity $\mathrm{V}-4 \mathrm{Cr}-4 \mathrm{Ti}$ large products, examinations of microstructures with SEM and TEM were carried out during the breakdown and the following thermal and mechanical treatment processes. The resulting alloys (NIFS-HEAT-1 and 2 with $\mathrm{C}, \mathrm{O}, \mathrm{N}$ of 56-69, 148-181 and 103-122 wppm, respectively) were subject to various cold rolling and heat treatment, followed by microstructural observations, Vickers hardness measurements, tensile tests at room temperature, and Charpy impact tests at $77 \mathrm{~K}$.

Two-step heat treatments, i.e. solid solution followed by re-precipitation, can control the impurity level in solution, and precipitate size and density. The yield strength and microstructures of $\mathrm{V}-4 \mathrm{Cr}-4 \mathrm{Ti}$ (NIFS-HEAT-2) were examined after heat treatments at $1373 \mathrm{~K}$ for an hour and the following re-heating for an hour at various temperatures. Note that the heat treatment at $1373 \mathrm{~K}$ resulted in dissolution of the thin Ti-O-C precipitates. The yield stress was increased by the formation of high density of fine precipitate (precipitate hardening) with its peak at $\sim 973 \mathrm{~K}$. At $873 \mathrm{~K}$ high density of fine precipitates were also observed in dark-field imaging conditions. The precipitate density and the yield stress decreased with the increase in temperature. The yield stress was again increased above $1173 \mathrm{~K}$ by the increase in the impurity in solution (solid solution hardening). The change in the yield stress with the temperature of the second annealing can be explained qualitatively by the combination of the two hardening mechanisms.

For the purpose of enhancing the high temperature strength further, combined heat treatment and cold working were given to V-4Cr-4Ti (NIFS-HEAT-2). Three types of heat treatment, SA (Solution Annealing, $1373 \mathrm{~K}, 1 \mathrm{~h}$ ), CP (Coarsened Precipitation, 1223K, lh) and FP (Fine Precipitation, 1373K, lh followed by $873 \mathrm{~K}, 10 \mathrm{~h}$ ) were provided. Fig. 1 shows Vickers Hardness of SA, CP and FP specimens with and without the following $20 \%$ cold working, as a function of the temperature of annealing for lh before the hardness test. Comparing to CP (standard heat treatment), SA and FP enhanced the hardness. The hardness of SA and FP specimens increased by annealing at $\sim 973 \mathrm{~K}$. With additional $20 \%$ cold working, the hardness was increased further in the all cases. Especially, SA or FP with $20 \%$ cold working resulted in significantly enhanced hardness. Their hardness decreased with the annealing temperature above $973 \mathrm{~K}$ but is higher than that of $\mathrm{CP}$ throughout the temperatures examined.

The present study showed that high degree of working to form thin and dense band structure of precipitates are necessary for having good impact property. In the fabrication process of fusion components the breakdown process should be carefully designed to provide the structural vanadium alloys with enough total working degree.

The enhanced high temperature strength of the specimens subject to combined solid solution annealing, precipitation annealing and cold working shows potential improvement of the vanadium alloys. Systematic characterization of the specimens, including low temperature fracture properties and thermal creep properties, is necessary for validation of the procedure.

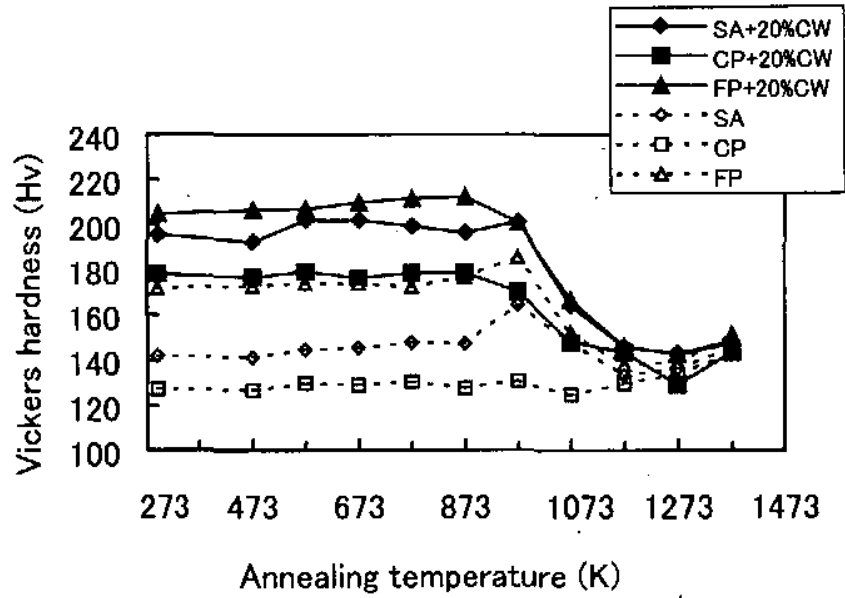

Fig. 1 Vickers hardness as a function of annealing temperature for $1 \mathrm{~h}$, for $\mathrm{V}-4 \mathrm{Cr}_{\mathrm{T}}-4 \mathrm{Ti}$ (NIFS-HEAT-2) with various heat treatments and cold working $(\mathrm{CW})$. SA: $1373 \mathrm{~K}, 1 \mathrm{~h}, \mathrm{CP}: 1223 \mathrm{~K}$, 1h, FP: $1373 \mathrm{~K}, 1 \mathrm{~h}$ followed by $873 \mathrm{~K}, 10 \mathrm{~h}$. 